\title{
Standounkt
}

\section{Auf dem Weg zu einem nachhaltigen Bankwesen?}

\author{
Die Finanzkrise hat das Versagen der Banken bei der Risiko- \\ kontrolle deutlich gemacht. Der neue internationale Standard \\ Basel-III soll die Situation verbessern. Aber er ist nur ein erster, \\ kleiner Schritt auf dem Weg zu einem nachhaltigen Bankwesen. \\ Von Markus Henn
}

D amit Banken nachhaltig wirtschaften, müssen sie ihre Risiken angemessen kontrollieren, das heißt bewerten und besichern. Dies ist in der liberalisierten, globalen Finanzwelt ein immer komplexerer und undurchsichtigerer Vorgang geworden, kurz gesagt: Keiner blickt mehr durch. Die Banken rechneten bis zur Krise munter ihre Risiken klein, verließen sich blind auf Ratingagenturen, versteckten Risiken in Schattenfinanzplätzen und hielten immer weniger Eigenkapital, das ihnen im Verlustfall zur Verfügung steht. Das Ergebnis ist bekannt.

\section{Die Reaktion auf die Finanzkrise}

Die Vorgaben zu Eigenkapital und Risikokontrolle vom Baseler Ausschuss für Bankenaufsicht, oft Basel-II genannt, haben sich in der Europäischen Union (EU) als wirkungslos oder, was Ratings angeht, gar schädlich erwiesen. Auch in den USA, wo Basel-II nicht umgesetzt war, ging es völlig schief. Das fehlende Eigenkapital wurde dann den Banken aus Steuergeldern gegeben. Um ein erneutes derartiges Totalversagen der Banken und Finanzmärkte zu verhindern, wurde 2010 Basel-III beschlossen. Im Juli 2011 präsentierte die EU-Kommission ihren Entwurf zur Umsetzung der neuen Vorgaben, der nun von Parlament und Rat verhandelt wird. Ohnehin würden die Kernbestimmungen aber erst 2019 volle Anwendung finden. Es ist also viel Zeit für alte und neue riskante Geschäfte.
Die wichtigsten Vorgaben von BaselIII sollen in der EU in einer Verordnung stehen, also direkt EU-weit gültig sein. $\mathrm{Zu}$ diesen Vorgaben gehören eine engere Definition und Erhöhung des harten Kernkapitals auf 4,5 Prozent (dafür aber weniger Ergänzungskapital), 2,5 Prozent Risikopuffer, ausreichend hochliquide Reserven und eine verschärfte Risikobewertung, insbesondere für außerbörsliche Derivate und Verbriefungen. Weitere Vorgaben sollen in eine EU-Richtlinie eingehen, die anschließend noch in den Mitgliedsstaaten umgesetzt werden müsste: zusätzliche Eigenkapitalvorgaben, vor allem für systemisch wichtige Banken, zusätzliche interne Prozesse, unter anderem statt der Verwendung externer Ratings und schließlich eine Hebelgrenze (leverage ratio) für das Verhältnis des Eigenkapitals zu den gesamten Geschäftspositionen.

\section{Eigenkapitalquote erhöhen}

Basel-III ist ein Fortschritt, vor allem für die Kontrolle der privaten Großbanken und Landesbanken, die besonders unnachhaltig agiert haben. Gewisse Geschäfte und Bilanzexzesse wären damit nicht mehr möglich. Allerdings könnte auch ein Eigenkapital von, wie vorgesehen, maximal 13 Prozent beleibe nicht jeden Kollaps verhindern. So hätte Lehman Brothers kurz vor dem Zusammenbruch Basel-III durchaus erfüllt. Zu Recht fordern deshalb immer mehr Ökonomen, dass die Eigenkapitalquoten zumindest für Großbanken deutlich höher sein müssen, 20 oder gar 30 Prozent. Die Schweiz hat ihren Banken auch schon deutlich mehr vorgeschrieben als bei Basel-III nötig, Großbritannien will dies ebenfalls tun. Andererseits könnten die auf das Versagen der Großbanken zugeschnittenen und für diese sinnvollen Vorgaben mancher sozial-ökologischen Alternativbank das Leben schwer machen. Eine Bank wie die GLS muss, obwohl sie in der Krise keine Probleme hatte, fürchten, ihre stillen Einlagen nicht mehr anerkannt zu bekommen.

\section{Basel III ist unzureichend}

Viele andere Probleme werden durch Basel-III nicht oder nicht ausreichend angegangen. Schattenfinanzplätze können von den Banken weiter genutzt werden, Schattenbanken wie Fonds sind gar nicht wirksam erfasst, und der riskante Eigenhandel ist den Banken auch nicht untersagt. Das Kernproblem einer strengeren Risikobewertung wird nur halbherzig angegangen, zum Beispiel wird die Verwendung riskanter Derivate kaum infrage gestellt, obwohl dieses Geschäft blüht wie nie und gerade erst bei der UBS AG völlig daneben ging. Großbanken, die „zu groß zum Pleitegehen" sind, können fortbestehen.

Völlig fehlen Ansätze, die den Banken ökologische und soziale Kriterien für ihre Geschäfte vorschreiben oder deren Verwendung zumindest begünstigen würden. Basel-III bleibt somit nur ein kleiner, erster Schritt hin zu nachhaltigeren Banken.

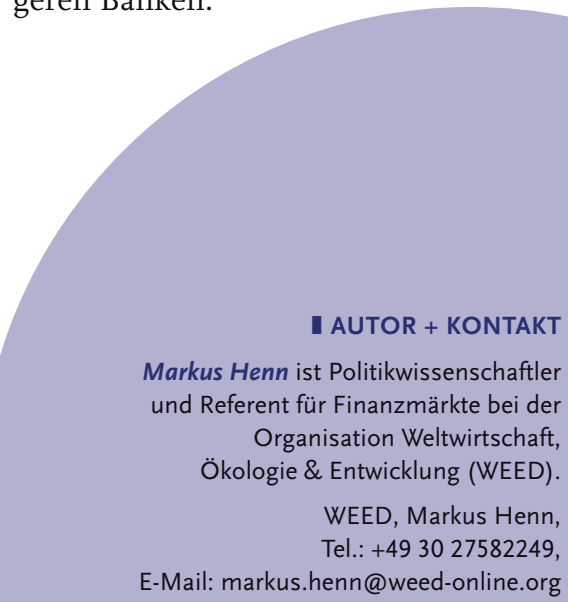




\section{Lizenzhinweis}

Die Beiträge in ÖkologischesWirtschaften werden unter der Creative-Commons-Lizenz "CC 4.0 Attribution Non-Commercial No Derivatives" veröffentlicht. Im Rahmen dieser Lizenz muss der Autor/Urheber stets genannt werden, das Werk darf nicht bearbeitet, abgewandelt oder in anderer Weise verändert und außerdem nicht kommerziell genutzt werden. Die digitale Version des Artikels bleibt für zwei Jahre Abonnent/innen vorbehalten und ist danach im Open Access verfügbar. 